\title{
Proteolytic Inactivation of LL-37 by Karilysin, a Novel Virulence Mechanism of Tannerella forsythia
}

\author{
Joanna Koziel ${ }^{a} \quad$ Aabdulkarim Y. Karim ${ }^{a}$ Kornelia Przybyszewska ${ }^{a}$

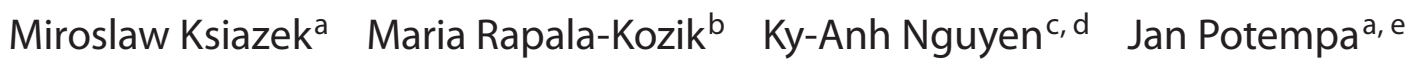 \\ Departments of a Microbiology and ${ }^{b}$ Analytical Biochemistry, Faculty of Biochemistry, Biophysics and \\ Biotechnology, Jagiellonian University, Krakow, Poland; ' Institute of Dental Research, Westmead Centre for Oral \\ Health, and d Faculty of Dentistry, University of Sydney, Sydney, N.S.W., Australia; ' University of Louisville School of \\ Dentistry, Oral Health and Systemic Disease, Louisville, Ky., USA
}

\section{Key Words}

Innate immunity - Antimicrobial peptide - Cathelicidin •

Metalloprotease $\cdot$ Tannerella forsythia $\cdot$ Inflammation .

Infection • Periodontitis quently, the karilysin protease may directly contribute to periodontal tissue damage and the development and/or progression of chronic periodontitis.

Copyright $\odot 2010$ S. Karger AG, Basel

\section{Introduction}

Antimicrobial peptides are components of innate immunity and are effective against gram-negative and gram-positive bacteria, parasites, fungi and some viruses $[1,2]$. In mammals, antimicrobial peptides were also found to function as immunomodulators of the innate immune system, as they modulate expression of chemokines and cytokines, as well as eliciting or inhibiting proinflammatory responses $[3,4]$. Since the recognition of their immunoregulatory functions, antimicrobial peptides are often referred to as host defense peptides. In the human oral cavity, several kinds of antimicrobial peptides are found, including $\alpha$ - and $\beta$-defensins, histatins and LL-37 [5].

Periodontal disease is a common bacteria-induced inflammatory disease in which the tooth-supporting connective tissues are progressively destroyed [6]. Antimi-

\section{KARGER}

Fax +4161306 1234

E-Mail karger@karger.ch

www.karger.com
(C) 2010 S. Karger AG, Basel

Accessible online at: www.karger.com/jin
Dr. Joanna Koziel

Faculty of Biochemistry, Biophysics and Biotechnology Jagiellonian University

ul. Gronostajowa 7, PL-30-386 Krakow (Poland)

Tel. +48 12664 6377, Fax +48 12664 6904, E-Mail joanna.koziel@uj.edu.pl 
crobial peptides produced by mucosal epithelium appear to play a pivotal role in the host innate immune defense in the oral cavity. The best example is morbus Kostmann syndrome, in which deficiency of LL-37 in neutrophils and saliva has been correlated with the occurrence of severe periodontal disease [7].

Tannerella forsythia (previously Bacteroides forsythus) is a gram-negative bacterium strongly associated with periodontitis [8]. To date, only a few virulence factors of T. forsythia have been recognized, including a sialidase (SiaHI), a cysteine protease with hemolysin activity (PrtH), a trypsin-like protease and an extracellular protein, BspA, mediating the attachment to fibronectin and fibrinogen [9-11]. Analysis of the T. forsythia genome revealed the presence of numerous open reading frames encoding putative proteases. Recently, we showed that one of these genes (Los Alamos Oral Pathogens Database Accession No. TF0367) encodes for a proteolytically active matrix metalloprotease-like enzyme designated karilysin [12]. Metalloproteases derived from microbial pathogens have been documented as important virulence factors contributing to evasion of antimicrobial mechanisms of the innate immune system [13]. The latter strategy is often executed by proteolytic inactivation of antibacterial peptides, including LL-37. Therefore, in this study, we investigated the potential of karilysin to interfere with the antibacterial and anti-inflammatory functions of LL-37.

\section{Materials and Methods}

\section{Peptide Synthesis}

LL-37 was commercially synthesized by Peptide 2.0 (Chantilly, Va., USA) on an Applied Biosystems model 433A synthesizer on a scale of $0.1-0.25 \mathrm{mmol}$, using tert-butoxycarbonyl chemistry and HPLC purified on C18 silica columns. The structural integrity of the peptide was confirmed by mass spectrometry. The peptide concentration was determined by quantitative amino acid analysis, and then it was lyophilized in the form of trifluoroacetate salt and stored at $4{ }^{\circ} \mathrm{C}$. Stock solutions $(6 \mathrm{mg} / \mathrm{ml})$ were prepared in phosphate-buffered saline for the evaluation of antimicrobial activity and were stored frozen at $-20^{\circ} \mathrm{C}$ in $1-\mathrm{ml}$ aliquots to be ready for use.

Recombinant Karilysin Expression, Purification and Activity Determination

Karilysin expression (both wild-type and catalytic Glu136Ala mutant forms) in an Escherichia coli host and subsequent purification was performed as described previously [12]. The activity of the purified enzymes was examined by cleavage of the fluorescent-labeled azocasein. To block karilysin activity, EDTA or $o$ phenanthroline at 10 and $5 \mathrm{mM}$, respectively, were used to inhibit karilysin. Using the limulus test, karilysin preparations were shown to be free of lipopolysaccharide (LPS).

Inactivation of LL-37 by Metalloprotease of T. forsythia

\section{LL-37 Cleavage by Karilysin}

LL-37 (5 $\mu \mathrm{g})$ was incubated with karilysin (5-500 ng) at peptide/enzyme molar ratios from 100:1 to 10,000:1 in $20 \mu \mathrm{l}$ of 100 $\mathrm{mM}$ Tris- $\mathrm{HCl}$ and $5 \mathrm{mM} \mathrm{CaCl}_{2}, \mathrm{pH} 8.0$, for $16 \mathrm{~h}$ at $37^{\circ} \mathrm{C}$. For time dependency experiments, LL-37 was exposed to karilysin action for $0,2,4,8,12$ and $16 \mathrm{~h}$ at a ratio of 1,000:1 (5 $\mu \mathrm{g}$ of LL-37 + 50 ng of karilysin) under the same conditions. Following incubation, the reaction was terminated by the addition of $1 \mathrm{M} \mathrm{HCl}$ (for HPLC experiments) or SDS-PAGE sample buffer, and after the denaturation step $\left(95^{\circ} \mathrm{C}\right.$ for $\left.5 \mathrm{~min}\right)$, samples were subjected to SDS-PAGE. LL-37 alone and LL-37 incubated with karilysin in the presence of $5 \mathrm{mM} o$-phenanthroline served as controls. Degradation products of LL-37 were resolved by HPLC.

\section{Reverse-Phase HPLC}

Twenty microliters of karilysin-digested LL-37 from each time point (as indicated above) were separated on a Supelcosil LC-318 column $(25 \mathrm{~cm} \times 4.6 \mathrm{~mm}$; Supelco). The elution was conducted using a 2 -solvent system, i.e. $0.1 \%$ trifluoroacetic acid $/ \mathrm{H}_{2} \mathrm{O}$ (solvent $\mathrm{A}$ ) and $80 \%$ acetonitrile $/ 0.08 \%$ trifluoroacetic acid (solvent B), at a constant flow rate of $0.5 \mathrm{ml} / \mathrm{min}$ with a $10-70 \%$ gradient of solvent B over $70 \mathrm{~min}$. UV absorbance was monitored at 215 $\mathrm{nm}$, and fractions were collected at $0.5-\mathrm{min}$ intervals.

\section{Antimicrobial Assay}

A colony reduction assay using E. coli (ATCC 33694) and Porphyromonas gingivalis W83, grown in LB and Schaedler Broth, respectively, was conducted to evaluate the antibacterial activity of LL-37. The E. coli and P. gingivalis cells were collected by centrifugation $(5,000 \mathrm{~g}, 8 \mathrm{~min})$, washed with phosphate-buffered saline and resuspended to a final concentration of $1 \times 10^{6}$ and $5 \times$ $10^{6}$ colony-forming units/ml (10\% Hank's balanced salt solution/ RPMI), respectively. LL-37 (22 $\mu \mathrm{M})$, either intact or after preincubation with karilysin, was prepared in $100 \mathrm{mM}$ Tris-HCl, pH 8.0, with $5 \mathrm{mM} \mathrm{CaCl}_{2}$, and 20 - $\mu$ l aliquots were transferred to low-protein-binding polypropylene tubes. To each tube, $180 \mu \mathrm{l}$ of the bacterial suspension was added. The plates were incubated at $37^{\circ} \mathrm{C}$. After $1 \mathrm{~h}$ of incubation, aliquots were plated onto tryptic soy agar plates or Schaedler agar with 5\% sheep blood for colony counting. All experiments were performed in triplicate.

\section{Cell Culturing}

Human monocyte-derived macrophages (hMDMs) were separated from fractions of peripheral blood mononuclear cells as described previously [14]. Peripheral blood mononuclear cells were seeded into 24-well plates and cultured in RPMI-1640 medium supplemented with $10 \%$ heat-inactivated autologous human plasma, $2 \mathrm{~mm}$ L-glutamine and $50 \mu \mathrm{g} / \mathrm{ml}$ gentamicin (Sigma) in a humidified atmosphere of $5 \% \mathrm{CO}_{2}$. After $24 \mathrm{~h}$, nonadherent cells were removed and adherent monocytes were differentiated to macrophages for 7-10 days, with fresh medium changes every second day. The hMDM phenotype was verified after nonenzymatic detachment of cells by immunofluorescent staining of CD14 (Dako Cytomation), CD16 (Dako Cytomation), CD11b (Becton Dickinson) and CD209 (Becton Dickinson) and subsequent flow cytometry analysis [14].

\section{TNF- $\alpha$ Release}

For TNF- $\alpha$ measurement, $0.3 \times 10^{6} \mathrm{hMDMs}$ in $500 \mu \mathrm{l}$ of RPMI-1640 supplemented with $0.2 \%$ autologous human plasma, 

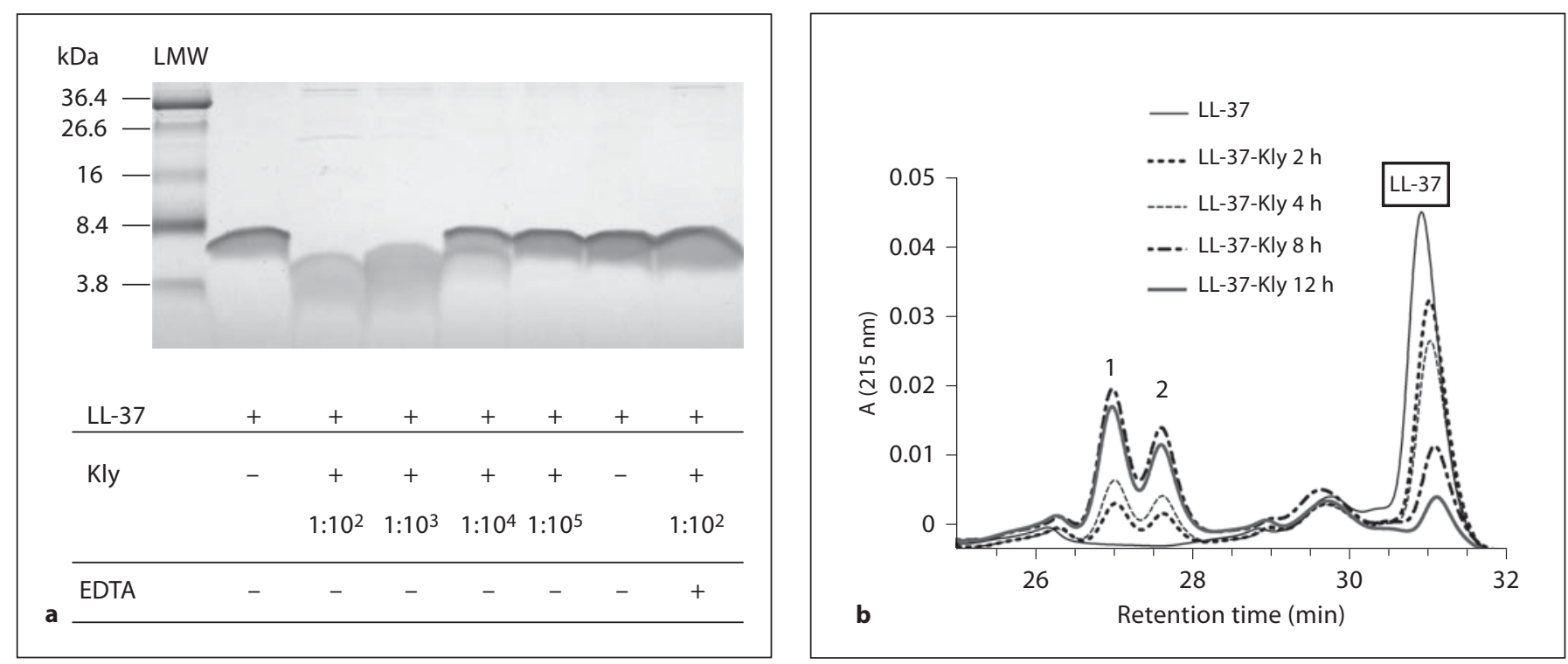

Fig. 1. Degradation of LL-37 by karilysin. a Dose-dependent degradation of LL-37 by karilysin (Kly). Karilysin (0.5-500 ng) was incubated with LL-37 (5 $\mu \mathrm{g})$ at molar ratios from 1:100 to 1:100,000 for $12 \mathrm{~h}$. b HPLC chromatogram of karilysin-treated LL-37. A = Absorbance. Representative data from 3 independent experiments are shown.

$2 \mathrm{mM} \mathrm{L}$-glutamine and $50 \mu \mathrm{g} / \mathrm{ml}$ gentamicin were stimulated with E. coli LPS $(10 \mathrm{ng} / \mathrm{ml})$ for $6 \mathrm{~h}$ in a total volume of $500 \mu \mathrm{l}$ in the absence or presence of LL-37 $(2 \mu \mathrm{M})$ or the same amount of LL-37 previously preincubated with karilysin. The experiment was performed in triplicate. After $6 \mathrm{~h}$, media were harvested and kept at $-20^{\circ} \mathrm{C}$ until analysis. The content of TNF- $\alpha$ was estimated by ELISA performed according to a protocol provided by the manufacturer (R\&D Systems). Absorbance at $570 \mathrm{~nm}$ was subtracted from absorbance at $450 \mathrm{~nm}$ and the amount of cytokine was estimated according to the standard curve prepared from a known concentration of TNF- $\alpha$.

\section{Statistical Analysis}

Results were analyzed for statistical significance using the Student's t test. Differences were considered significant when $\mathrm{p}<$ 0.05 .

\section{Results}

\section{Degradation of LL-37 by Karilysin}

In humans, cathelicidin seems to play a key role in protecting the human periodontium against dental plaque bacteria. Therefore, we investigated if karilysin can degrade LL-37. To this end, the peptide was incubated with purified enzyme and samples were analyzed by SDS-PAGE. The analysis revealed that karilysin cleaves LL-37 in a concentration- and time-dependent manner (fig. 1), leading to the accumulation of product(s) with a lower molecular mass than the native LL-37. After $12 \mathrm{~h}$ of incubation, a partial cleavage was observed at a 1:10,000 molar ratio of karilysin to LL-37 (fig. 1a). At a 1:1,000 ratio, the majority of LL-37 was cleaved after $2 \mathrm{~h}$, but $12 \mathrm{~h}$ was needed for total conversion of the native peptide to lower-molecular-mass forms (fig. 1b). The degradation of LL-37 by karilysin was totally inhibited by EDTA (fig. 1a) and $o$-phenanthroline (data not shown). Significantly from the physiopathological point of view, karilysin also cleaved LL-37 in the presence of 10\% human plasma. In this case, however, a higher concentration of the enzyme was needed to achieve the same degree of peptide cleavage as in the medium alone (data not shown).

\section{Inhibition of Antibacterial Activity of LL-37 by Karilysin}

T. forsythia is resistant to the antibacterial activity of LL-37 at concentrations up to $10 \mu \mathrm{g} / \mathrm{ml}(2.2 \mu \mathrm{M})$ (data not shown), and cleavage by karilysin may contribute to this resistance. Therefore, we analyzed the bactericidal activity of LL-37 after incubation with karilysin using $E$. coli and $P$. gingivalis as targets and found that karilysin efficiently inactivated the antibacterial activity of LL-37 in a concentration- and time-dependent manner (fig. 2). The loss of function correlated well with the level of 


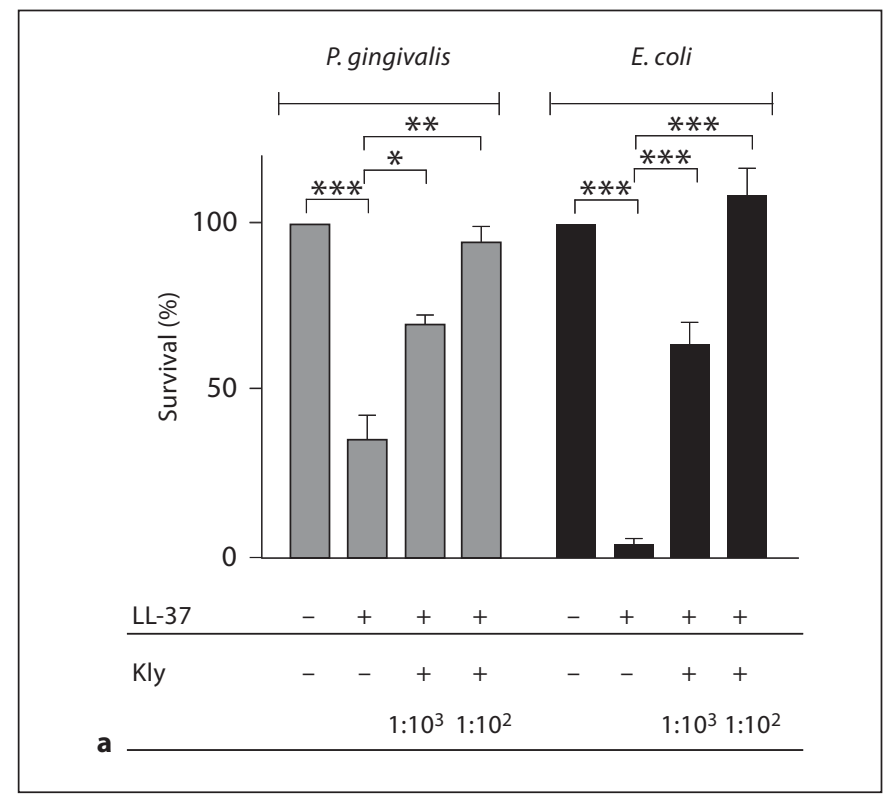

Fig. 2. Effect of karilysin treatment on antibacterial activity of LL-37 against $P$. gingivalis W83 and E. coli (ATCC 25922). LL-37 was incubated alone or with karilysin (Kly) at a molar ratio of 1,000:1 or 100:1 for $12 \mathrm{~h}$ (a) and at a molar ratio of 1,000:1 for 2, $4,6,8$ and $12 \mathrm{~h}$ (b) then mixed with bacteria, incubated for $1 \mathrm{~h}$ at $37^{\circ} \mathrm{C}$ and plated onto agar plates to determine the numbers of

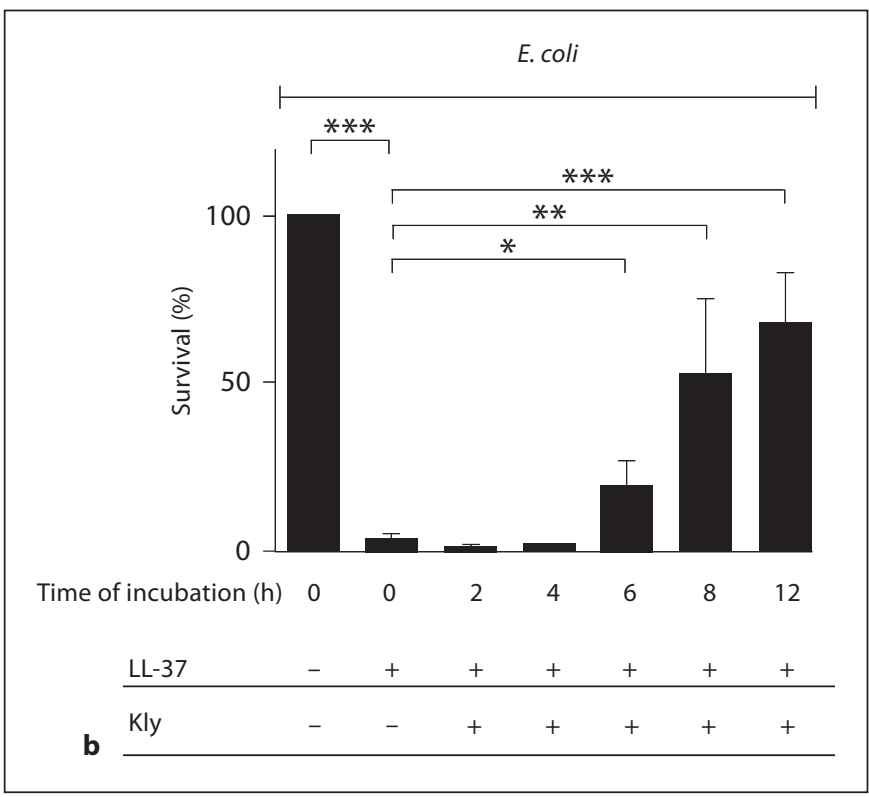

colony-forming unites. Percentage survival was calculated and compared to bacteria grown without antimicrobial peptide LL-37 (100\% survival). Mean values and standard deviations (error bars) of 3 independent experiments performed in duplicate are shown. ${ }^{*} \mathrm{p}<0.05 ;{ }^{* *} \mathrm{p}<0.01 ;{ }^{* * *} \mathrm{p}<0.001$. cleavage of native LL-37 observed by SDS-PAGE (fig. 1a) and HPLC analysis (fig. 1b). Nevertheless, it should be noted that total inactivation of LL-37 bactericidal activity against $E$. coli was achieved only when the enzyme was incubated with the peptide at a 1:100 molar ratio. At a 1:1,000 ratio and with a long incubation time $(12 \mathrm{~h})$, the efficiency of E. coli killing by cleaved LL-37 was maximally reduced by $70 \%$ (fig. 2 b).

\section{Attenuation of Anti-Inflammatory Activity of LL-37 by Karilysin}

Apart from being bactericidal, LL-37 possesses potent anti-inflammatory activity. This is mediated through direct binding of LL-37 to LPS [15]. Since stimulation of macrophages with LPS leads to the release of several proinflammatory mediators, including TNF- $\alpha$, we used these systems to determine how cleavage of LL-37 by karilysin affected the peptide's ability to neutralize LPS. As expected, native LL-37 at $2 \mu \mathrm{M}$ totally abrogated LPSinduced release of TNF- $\alpha$ by hMDMs (fig. 3a). The peptide treatment with karilysin caused a dose-dependent inactivation of the ability of LL-37 to neutralize LPS. Even at very low concentrations of the enzyme (enzyme to peptide ratio of $1: 10,000)$, a significant decrease in LL37 anti-inflammatory activity was observed, while LL37 function was obliterated at the 1:100 molar ratio (fig. 3a). Inactivation of LL-37 was dependent on karilysin proteolytic activity, since the presence of $o$-phenanthroline protease inhibitor annihilated the effect of karilysin on LL-37 and a catalytically inactive karilysin mutant (karilysin ${ }^{\mathrm{E} 136 \mathrm{~A}}$ ) had no effect on neutralization of LPS by LL-37. Together, our findings indicated that the proteolytic truncation of LL-37 by karilysin effectively inactivates the biological activity of this peptide (fig. 3a).

The next obvious question to be asked was whether LL-37 in complex with LPS is susceptible to cleavage by karilysin and whether proteolysis of the peptide would release LPS from the complex to induce proinflammatory activity. To answer the question, we incubated the LL-37/LPS complex with karilysin and tested the reaction mixture for LPS-driven secretion of TNF- $\alpha$. We observed a dose-dependent release of active LPS from the complex with LL-37 as manifested by TNF- $\alpha$ secretion by hMDMs (fig. 3b). 


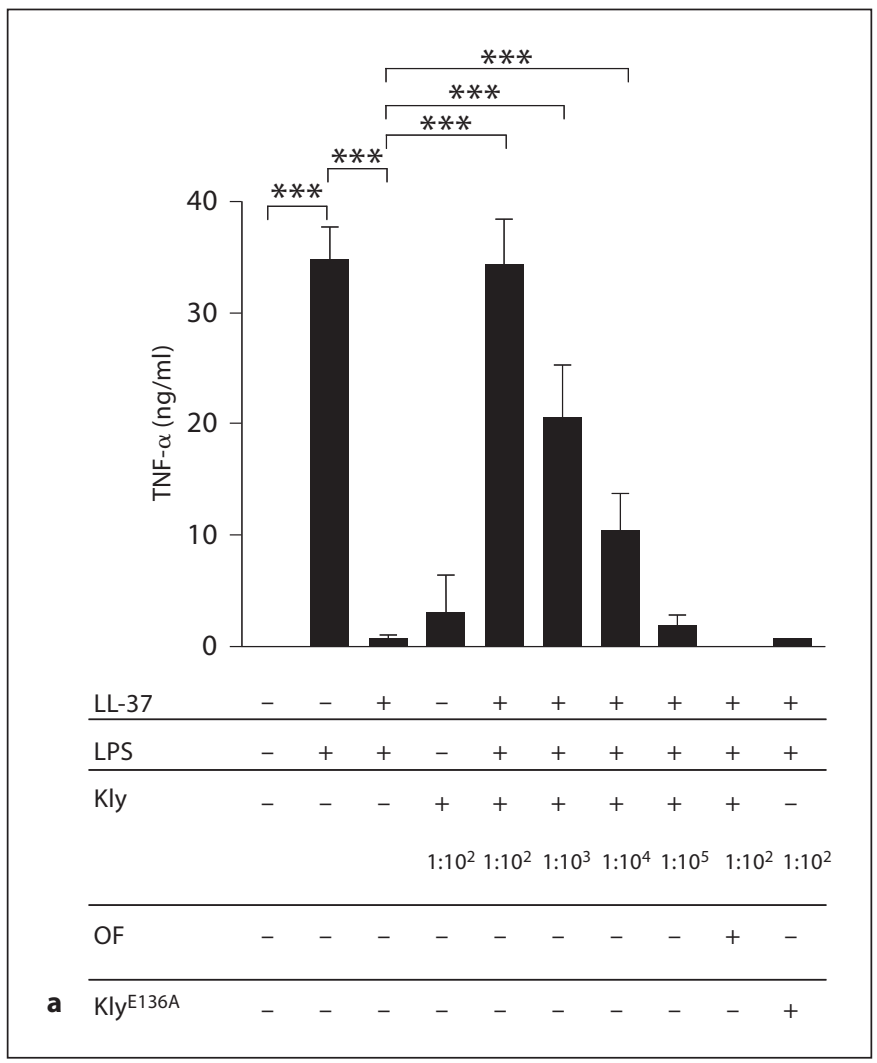

Fig. 3. Effects of LL-37 cleavage by karilysin on LPS-stimulated TNF- $\alpha$ secretion. a Macrophages were stimulated for $6 \mathrm{~h}$ with 10 ng/ml E. coli LPS, native LL-37, LL-37 digested with karilysin (Kly) at molar ratios from 1:100 to 1:100,000 for $12 \mathrm{~h}, \mathrm{LL}-37$ treated with the catalytically inactive form of karilysin $\left(\mathrm{Kly}^{\mathrm{E} 136 \mathrm{~A}}\right)$ or karilysin inhibited by treatment with $o$-phenanthroline (OF). Supernatants were analyzed for TNF- $\alpha$ using ELISA. $\mathbf{b}$ LPS was first preincubated with LL-37 for $2 \mathrm{~h}$, the complex was treated with

\section{Discussion}

In the oral cavity, especially on the tooth surface below the gum line, LL-37 seems to play a crucial role in controlling the colonization of the subgingival dental plaque by pathogenic species, since deficiency of LL-37, either genetic or locally induced, is associated with severe periodontitis [7]. In this study, we have shown that karilysin, a metalloprotease from T. forsythia, can inactivate the bactericidal activity of LL-37 in a time- and concentration-dependent manner through limited proteolysis. Since karilysin can cleave LL-37 in the presence of human plasma, the reaction may take place in vivo. In keeping with this, cathelicidin (the precursor of LL-37) is often found as a truncated $11-\mathrm{kDa}$ form in chronic periodontitis lesions with a high load of T. forsythia [16]. Neverthe-

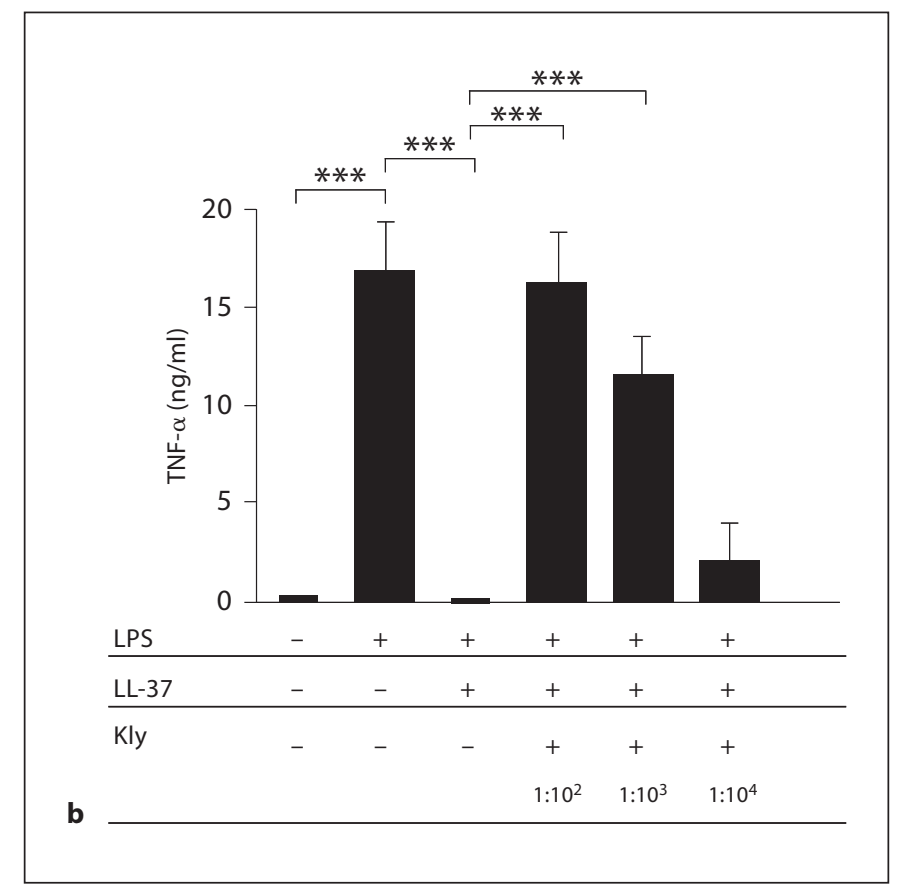

karilysin at molar ratios from 1:100 to $1: 10,000$ for $12 \mathrm{~h}$ and the digest was added to macrophages. As controls, macrophages were stimulated with $10 \mathrm{ng} / \mathrm{ml}$ E.coli-derived LPS, LL-37 or karilysin. Conditioned media were harvested after $6 \mathrm{~h}$ and the TNF- $\alpha$ concentration was determined using ELISA. Data are the mean $\pm \mathrm{SD}$ values from 3 independent experiments, each performed at least twice. ${ }^{* *} \mathrm{p}<0.001$.

less, it must be kept in mind that in vivo, several proteases produced by other periodontopathogens can also degrade bactericidal peptides [17]. Finally, numerous other proteases are known to be encoded in the T. forsythia genome, which, if expressed in vivo, may themselves contribute to LL-37 inactivation. Taken together, the combined action of microbial proteases aimed at bactericidal peptides, including LL-37, may effectively protect Fusobacterium nucleatum, Streptococcus mutans, Streptococcus sobrinus and Streptococcus salivarius, which are highly susceptible to the bactericidal activity of LL-37 [18] but nevertheless thrive in dental plaque bathed in gingival crevicular fluid containing elevated amounts of these peptides.

Apart from its direct bactericidal activity, LL-37 possesses the ability to quench inflammatory reactions by 
neutralizing LPS [19]. This function of LL-37 is most likely to be important in periodontitis sites heavily colonized by a large variety of gram-negative bacteria. The anti-inflammatory effect and the bactericidal activity of LL-37 were inactivated by karilysin with similar efficiencies. Karilysin was also capable of releasing LPS from the biologically inert LPS/LL-37 complexes, thus partly restoring the proinflammatory activity of the endotoxin. Therefore, proteolytic inactivation of LL-37 by karilysin and other host and periodontal-pathogen-derived proteases [20] may contribute to the maintenance of the local inflammatory reaction through LPS-induced release of proinflammatory cytokines. In summary, it is clear that by inactivating LL-37, karilysin may play an important role in immune evasion of $T$. forsythia and contributes to the development of the chronic inflammatory response characteristic of periodontitis.

\section{Acknowledgements}

This study was supported by grants DE 09761 (to J.P. and K.A.N.) and 1642/B/P01/2008/35 (to J.P.) from the National Institutes of Health, USA, and the Department of Scientific Research, Polish Ministry of Science and Education, respectively. The Faculty of Biochemistry, Biophysics and Biotechnology of the Jagiellonian University is a beneficiary of structural funds from the European Union (grant no. POIG.02.01.00-12-064/08: 'Molecular biotechnology for health').

\section{References}

$>1$ Hancock RE, Sahl HG: Antimicrobial and host-defense peptides as new anti-infective therapeutic strategies. Nat Biotechnol 2006; 24:1551-1557.

-2 Ding J, Chou YY, Chang TL: Defensins in viral infections. J Innate Immun 2009;1:413420.

$>3$ Pistolic J, Cosseau C, Li Y, Yu J, Filewod NCJ, Gellatly S, Rehaume LM, Bowdish DME, Hancock REW: Host defense peptide LL-37 induces IL- 6 expression in human bronchial epithelial cells by activation of the NF- $\kappa \mathrm{B}$ signaling pathway. J Innate Immun 2009; 1 254-267.

4 Scott MG, Dullaghan E, Mookherjee N, Glavas $\mathrm{N}$, Waldbrook M, Thompson A, Wang A, Lee K, Doria S, Hamill P, Yu JJ, Li Y, Donini O, Guarna MM, Finlay BB, North JR, Hancock RE: An anti-infective peptide that selectively modulates the innate immune response. Nat Biotechnol 2007;25:465-472.

$\checkmark 5$ Hosokawa I, Hosokawa Y, Komatsuzawa H, Goncalves RB, Karimbux N, Napimoga MH, Seki M, Ouhara K, Sugai M, Taubman MA, Kawai T: Innate immune peptide LL-37 displays distinct expression pattern from betadefensins in inflamed gingival tissue. Clin Exp Immunol 2006;146:218-225.

6 Flemming TF: Periodontitis. Ann Periodontol 1999;4:32-37.

$>7$ Putsep K, Carlsson G, Boman HG, Andersson M: Deficiency of antibacterial peptides in patients with morbus Kostmann: an observation study. Lancet 2002;360:11441149.
8 Tanner ACR, Izard J: Tannerella forsythia, a periodontal pathogen entering the genomic era. Periodontol 2000 2006;42:88-113.

$\checkmark 9$ Saito T, Ishihara K, Kato T, Okuda K: Cloning, expression and sequencing of a protease gene from Bacteroides forsythus ATCC 43037 in Escherichia coli. Infect Immun 1997;65: 4888-4891.

10 Grenier D: Characterization of the trypsinlike activity of Bacteroides forsythus. Microbiology 1995;141:921-926.

11 Sharma A, Sojar HT, Glurich I, Honma K, Kuramitsu HK, Genco RJ: Cloning, expression, and sequencing of a cell surface antigen containing a leucine-rich repeat motif from Bacteroides forsythus ATCC 43037. Infect Immun 1998;66:5703-5710.

12 Karim AY, Kulczycka M, Kantyka T, Dubin G, Jabaiah A, Daugherty PS, Thogersen IB, Enghild JJ, Nguyen K, Potempa J: A novel matrix metalloprotease-like enzyme (karilysin) of the periodontal pathogen Tannerella forsythia ATCC 43037. Biol Chem 2010;391: 105-117.

13 Potempa J, Pike RN: Corruption of innate immunity by bacterial proteases. J Innate Immun 2009;1:70-87.

-14 Koziel J, Maciag-Gudowska A, Mikolajczyk T, Bzowska M, Sturdevant DE, Whitney AR, Shaw LN, DeLeo FR, Potempa J: Phagocytosis of Staphylococcus aureus by macrophages exerts cytoprotective effects manifested by the upregulation of antiapoptotic factors. PLoS One 2009;4:e5210.

15 Scott MG, Vreugdenhil AC, Buurman WA, Hancock RE, Gold MR: Cutting edge: cationic antimicrobial peptides block the binding of lipopolysaccharide (LPS) to LPS binding protein. J Immunol 2000;164:549-553.
16 Puklo M, Guentsch A, Hiemstra PS, Eick S, Potempa J: Analysis of neutrophil-derived antimicrobial peptides in gingival crevicular fluid suggests importance of cathelicidin LL-37 in the innate immune response against periodontogenic bacteria. Oral Microbiol Immunol 2008;23:328-335.

$\checkmark 17$ Carlisle MD, Srikantha RN, Brogden KA: Degradation of human $\alpha$ - and $\beta$-defensins by culture supernatants of Porphyromonas gingivalis strain 381. J Innate Immun 2009; $1: 118-122$

-18 Ouhara K, Komatsuzawa H, Yamada S, Shiba H, Fujiwara T, Ohara M, Sayama K, Hashimoto K, Kurihara H, Sugai M: Susceptibilities of periodontopathogenic and cariogenic bacteria to antibacterial peptides, $\beta$-defensins and LL37, produced by human epithelial cells. J Antimicrob Chemother 2005;55:888896.

19 Molhoek EM, den Hertog AL, de Vries AM, Nazmi K, Veerman ECI, Hartgers FC, Yazdanbakhsh M, Bikker FJ, van der Kleij D: Structure-function relationship of the human antimicrobial peptide LL-37 and LL-37 fragments in the modulation of TLR responses. Biol Chem 2009;390:295-303.

20 Schmidtchen A, Frick IM, Andersson E, Tapper H, Björck L: Proteinases of common pathogenic bacteria degrade and inactivate the antibacterial peptide LL-37. Mol Microbiol 2002;46:157-168. 